\title{
HORTAS URBANAS E FAZENDAS VERTICAIS: A ARQUITETURA E A PRODUÇÃO DE ALIMENTOS
}

\author{
RODRIGUES, Andressa Caixeta \\ FAUeD/UFU, e-mail: andressa.caixeta.rodrigues@gmail.com \\ OLIVEIRA, Juliano Carlos Cecílio Batista \\ FAUeD/UFU, e-mail: julianooliveira.arq@gmail.com
}

\begin{abstract}
RESUMO
A pesquisa consiste em uma iniciação científica em estágio inicial, cujo objetivo é analisar os projetos arquitetônicos de hortas urbanas e fazendas verticais, bem como seus desdobramentos econômicos, ambientais e sociais. O foco é estudar a viabilidade de cultivar alimentos dentro das cidades brasileiras, através de edifícios contemporâneos com o emprego de tecnologia de ponta ou em terrenos e glebas por meio da agrofloresta. A metodologia é de base essencialmente bibliográfica, através da leitura e sistematização de projetos exemplares, além de algumas etapas de levantamento de campo e entrevistas com profissionais da área para discutir a eficiência da ideia. A dificuldade de acesso à uma boa alimentação, tanto pelas distâncias físicas quanto pela elevação de preços, assim como diversos outros problemas correlacionados podem ser resolvidos ou amenizados com fazendas verticais e hortas urbanas: prédios projetados ou adaptados para cultivar espécies para consumo dentro dos centros urbanos, gastando menos água e agrotóxicos, economizando espaço, reduzindo distâncias, gerando empregos e garantindo o abastecimento à prova de mudanças climáticas. Os resultados da pesquisa serão apresentados em forma de tipologias projetuais e gráficos que revelem a aplicação de espaços de tal natureza no contexto brasileiro, e de que maneira esses projetos indiretamente auxiliam em aspectos sociais e econômicos urgentes no cenário contemporâneo.
\end{abstract}

Palavras-chave: Hortas Urbanas, Fazendas Verticais, Sustentabilidade, Qualidade Ambiental

\begin{abstract}
The research consists of a scientific initiation in early stage, whose objective is to analyze the architectural projects of urban gardens and vertical farms, as well as their economic, environmental and social developments. The focus is to study the feasibility of growing food inside Brazilian cities through contemporary buildings using great technology or in wastelands through agroforestry. The method is essentially bibliographical, through the reading and systematization of exemplary projects, but with some steps of field survey and interviews with professionals of the area to discuss the efficiency of the idea. The difficulty of accessing good food, due to physical distances and price increases, as well as several other related problems, can be solved or softened with vertical farms and urban gardens: buildings designed or adapted to grow species for consumption within urban centers, spending less water and agrochemicals, saving space, reducing distances, generating jobs and ensuring climate-proof supplies. The research results will be structured in the presentation of architectural typologies and graphics which reveal the applicability of such spaces in Brazilian context, and how should these projects contribute to assist urgent social and economic aspects in the contemporary scenario.
\end{abstract}

Keywords: Urban Horticulture, Vertical Farms, Sustainability, Environmental Quality

RODRIGUES, A. C.; OLIVEIRA, J. C. C. B. Hortas urbanas e fazendas verticais: a arquitetura e a produção de alimentos. In: SIMPÓSIO BRASILEIRO DE QUALIDADE DO PROJETO NO AMBIENTE CONSTRUÍDO, 6., 2019, Uberlândia. Anais... Uberlândia: PPGAU/FAUeD/UFU, 2019. p. 471-480. DOI https://doi.org/10.14393/sbqp19044. 


\section{INTRODUÇÃO}

De acordo com o departamento de pesquisa da Organização das Nações Unidas (ONU, 2017), no ano de 2050, a população mundial atingirá a marca de 9.8 bilhões. Além disso, o número de residentes em área urbana será aproximadamente o dobro do rural, uma estatística que era inversa logo antes da virada do milênio. Sabe-se que o ritmo de crescimento da humanidade desacelerou nas últimas décadas, mas os avanços tecnológicos não serão capazes de suprir a demanda de alimentos para todos os países se o modo de produção agrícola continuar cometendo os mesmos erros.

Fatores como o crescimento exponencial da população, modos de produção agrícola ultrapassados, dificuldades na distribuição de seus produtos, práticas agrícolas extensivas e o desperdício de aproximadamente 1/3 da comida do mundo impactam as perspectivas da alimentação no planeta. Essa realidade é agravada pela afirmação da ONU (2017) de que o problema da fome no mundo é essencialmente causado por conflitos sociopolíticos, clima, mádistribuição de recursos e desigualdade socioeconômica.

Diante de tal quadro e considerando que o ritmo atual da produção mundial de alimentos será insuficiente para abastecer a humanidade nas próximas décadas, verifica-se a demanda por maior conhecimento sobre soluções arquitetônicas que buscam minorar tais efeitos sobre a sociedade e o meio ambiente. Portanto, essa pesquisa busca orientar técnicos, trabalhadores e consumidores em como proceder com o projeto de tais espaços.

A urgência do tema se comprovou com a greve dos caminhoneiros, em maio de 2018, que revelou a sintomática dependência da população em relação ao abastecimento diário de mercadorias. O estado de relativa anomia nos supermercados tornou visível o despreparo dos brasileiros para lidar com uma situação de crise e o caos que seria uma interrupção prolongada de suprimentos

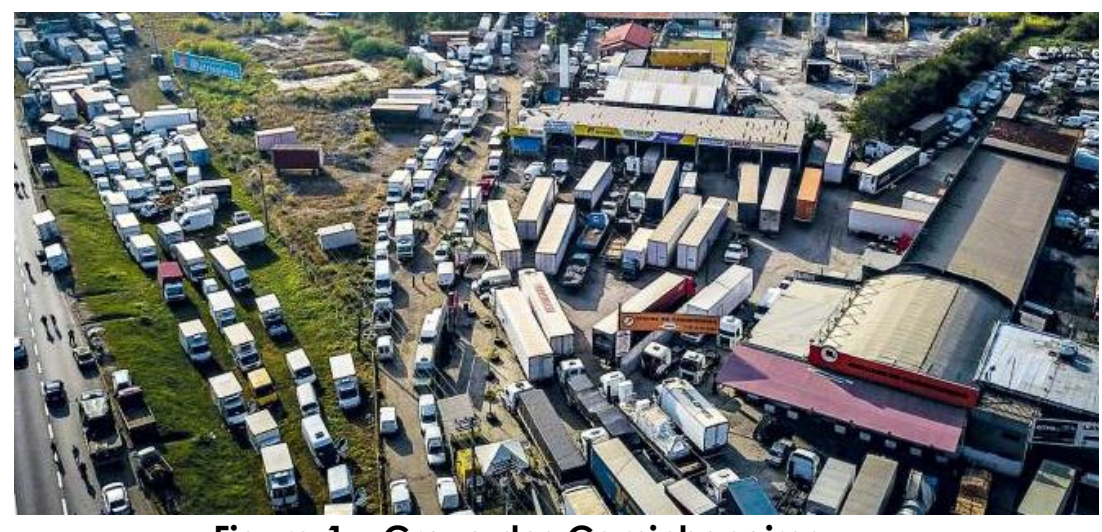

Figura 1 - Greve dos Caminhoneiros -

Fonte: Revista Veja (2018)

Agricultura Urbana e Periurbana (AUP) é o plantio de hortas em terrenos vazios, coberturas de edifícios e pequenas porções de terra nas cidades e arredores próximos, de maneira oposta às grandes plantações na zona rural. Nos latifúndios, essa agricultura extensiva se opõe artificialmente à dinâmica natural da vegetação, implica na regressão do número de espécies e destrói ou enfraquece os mecanismos homeostáticos. Também é possível relacionar a prática ao cultivo de orgânicos dentro ou próximo das cidades, à defesa da biodiversidade (COMITÊ INTERNACIONAL PARA O FUTURO DA ALIMENTAÇÃO E 
DA AGRICULTURA, 2006), e à redução do volume de lixo e gases tóxicos por meio da compostagem.

Há uma diferença conceitual entre os dois objetos de estudo: as fazendas verticais são edifícios destinados ao plantio de gêneros agrícolas nas metrópoles - prédios inteiros projetados ou reformados para cultivar espécies para consumo. E as hortas urbanas são canteiros em coberturas de edifícios, instituições, lotes vagos e vazios urbanos, adaptáveis a áreas menos densas e zonas de transição entre campo e cidade. Por isso este projeto propõe o estudo de fazendas verticais e hortas urbanas como uma das potenciais soluções para a sustentabilidade das cidades de vários portes, cabendo à arquitetura responder tecnicamente para a implantação dessa nova tipologia de edifício, certamente fundamental neste século XXI.

\section{METODOLOGIA}

A pesquisa aqui proposta é de natureza essencialmente bibliográfica (teóricaqualitativa), ainda que também se apoie em determinadas etapas em levantamento de campo. Uma primeira etapa consiste em pesquisa bibliográfica em livros, artigos, dissertações e teses referente a economia, sustentabilidade, agricultura, arquitetura e urbanismo sustentáveis. Também será fundamental a coleta de informações, análise de vídeos, infográficos e reportagens sobre fazendas verticais e hortas urbanas, registrando seus benefícios, formas de organização e principais problemas.

O trabalho realizará levantamento de dados em acervos textuais, cartográficos e fotográficos referente a situações urbanas viáveis para a aplicação de hortas urbanas ou fazendas verticais, seja considerando perspectivas de crescimento ou previsão de crise de abastecimento. Essa consulta será realizada com o auxílio da plataforma do IBGE e de trabalhos de estudantes de Geografia, Economia, Arquitetura e Urbanismo.

De modo quase concomitante à primeira etapa, a pesquisa também irá procurar agricultores e arquitetos que possam agregar informações relevantes para a pesquisa e entrevistá-los. Além disso, buscará viabilizar visitas ao campo de plantio, a hortas urbanas da região e a edifícios pioneiros na prática de AUP. Por fim, irá traduzir as descobertas da pesquisa em um instrumento de consulta didático e explicativo, para ajudar futuros arquitetos e agricultores na continuidade dos estudos para cidades produtivas e agradáveis.

\section{DISCUSSÃO}

Segundo a Food and Agriculture Organization of the United Nations (BENÍTEZ, 2018), 1.3 bilhão de toneladas de alimento são desperdiçadas por ano, o que equivale a $24 \%$ da produção mundial. Essa comida que vai para o lixo poderia alimentar 28,5\% da humanidade: mais de 2 bilhões de pessoas. Os números chamam a atenção: a comida desperdiçada gera um prejuízo de 750 bilhões de dólares; e 1.4 bilhão de hectares no Brasil, Argentina, México e Venezuela foram usados para produzir comida que não chegou a ser consumida.

A interdisciplinaridade da discussão exigiu busca e revisão de soluções tecnológicas sustentáveis e alternativas na plataforma da EMBRAPA (Empresa Brasileira de Pesquisa Agropecuária) consultando publicações científicas da Circular Técnica. Além disso, buscou-se a identificação de espécies de plantas 
com boa adaptabilidade ao ambiente controlado das estufas urbanas, considerando a quantidade de luz, tipos de solo e nutrientes e água necessários ao desenvolvimento das hortaliças. Além disso, coube analisar desdobramentos econômicos e ambientais gerados pela produção de alimentos nas cidades, como a redução do uso de água, a não-utilização de agrotóxicos, a geração de trabalho e renda alternativos para comunidades.

Segundo a FAO (ONU, 2017a), dos 1,3 bilhão de toneladas desperdiçadas, 10\% desse número ocorre no campo, $50 \%$ no manuseio e transporte, $30 \%$ na comercialização, e $10 \%$ no varejo e consumidor final. Se a comida fosse produzida dentro da cidade, em fazendas verticais e hortas urbanas, as duas etapas intermediárias seriam cortadas, reduzindo em aproximadamente $80 \%$ a comida jogada fora. A eficiência produtiva das áreas periurbanas deixaria de ser excessivamente testada, e os lucros deixariam de concentrar-se nos centros de distribuição como o CEASA (em Uberlândia) e o CEAGESP (em São Paulo).

Outro aspecto fundamental ao tema está na oferta de uma alimentação mais próxima do "Slow Food" do que do "Fast Food", nos preceitos do Movimento SIOW (MONTANER, 2011). Ou seja, incentivar uma rotina tranquila, qualificada e desacelerada, que busca a calma e a qualidade de vida, além de defender a importância da diversidade no espaço urbano (JACOBS, 1961), no contexto de cidades de grande e médio porte brasileiras. Com isso, há um reforço da prática AUP em espaços intra-urbanos e/ou nos arredores do município, de acordo com a gestão territorial e ambiental vigente, em terrenos particulares e públicos.

Compartilhando o espaço urbano de maneira mais eficiente, será possível restaurar o meio-ambiente e manter suficientes opções de comida saudável, mesmo que sejam objetivos aparentemente opostos. Produzir comida de forma naturalista por meio da agrofloresta em hortas urbanas; e de maneira tecnológica em estufas empilhadas verticalmente pode parecer desafiador, mas compensará o investimento financeiro e acadêmico em médio/longo prazo. "A eficiência de cada andar de uma fazenda vertical, um acre de terra, pode ser equivalente a dez, até vinte acres com cultivo tradicional, dependendo da plantação. O cultivo em estufas elimina a necessidade de combustíveis fosseis hoje usados para arar, aplicar fertilizantes, semear, capinar e colher" (DESPOMMIER, 2010, p. 5).

O principal contra-argumento à essas práticas é a viabilidade econômica. Em um cenário brasileiro, onde a comida é abundante e acessível, a maior parte da população vai optar pelo produto mais barato, desqualificando os produtos de hortas urbanas e fazendas verticais do mercado competitivo. No entanto, muitos países já possuem comida muito mais cara e de menor qualidade, além do fato de que os preços no mundo inteiro tendem a subir em um futuro próximo. Isso se deve ao eminente esgotamento dos combustíveis fósseis e consequente opção dos fazendeiros pela cana-deaçúcar e pelo milho para a produção de biocombustíveis. Isso significa mais lucro para eles e suas famílias, e menor disponibilidade de gêneros alimentícios naturais no mercado (INOVAÇÃO UNICAMP, 2011). Se o cenário mundial continuar assim, os produtos das fazendas e os das cidades apresentarão preços muito semelhantes. 


\section{ESTUDOS DE CASO}

No bairro de Berlin-Neukölln, pessoas de muitas gerações e países diferentes cultivam um jardim de canteiros suspensos em $5.000 \mathrm{~m}^{2}$ no antigo aeroporto Tempelhof. Hoje um parque, o local abriga milhares de refugiados que trabalham lado a lado com alemães no cultivo de plantas em carrinhos de bebê, tubos de zinco, caixotes de madeira e resíduos de construção civil (PISEAGRAMA, 2016). No Japão, hortas urbanas funcionam nas coberturas das estações de trem de Tóquio, parte do projeto Sodarofarm, que pretende criar um trajeto verde ao longo de toda a costa leste do país (ARCHDAILY, 2014). Enquanto isso, em Uberlândia (MG), 25 presidiários da Penitenciária Jacy de Assis cultivam mensalmente 400 caixas de legumes, hortaliças e plantas medicinais, servidas no local e vendidas para o bairro (THE GREEN POST, 2016). Existem incontáveis configurações diferentes de hortas urbanas em diferentes instituições no Brasil e no mundo, uma prática que incentiva a sustentabilidade, qualidade ambiental urbana, inclusão social, economias alternativas e lideranças distribuídas.

Agora vamos aos números: Em Itabirito (MG), foi construída uma estufa de 1 hectare com tecnologia importada da Holanda. O plantio funciona desde 2016, em vasos feitos de substrato de fibra de coco, com tomateiros de 6 variedades diferentes presos ao teto por cabos de aço. As estufas comuns têm as paredes e teto de plástico, o que permite a entrada de 80 a $85 \%$ de luz do Sol. No entanto, essa construção tem as vedações em vidro, o que permite a entrada de 95 a $98 \%$ de insolação. No caso do tomate, cada $1 \%$ a mais de insolação significa $1 \%$ a mais de produtividade. A nutrição das plantas funciona através de mangueiras que bombeiam uma solução de água misturada com nitrogênio, fósforo e potássio e o controle das condições externas é monitorado por computadores que acionam telas, ventiladores, janelas e até uma cobertura retrátil por automação. A produção desse único hectare gera 400 toneladas por ano, o que é 4 a 5 vezes mais do que um cultivo convencional à céu aberto (GLOBO RURAL, 2017).

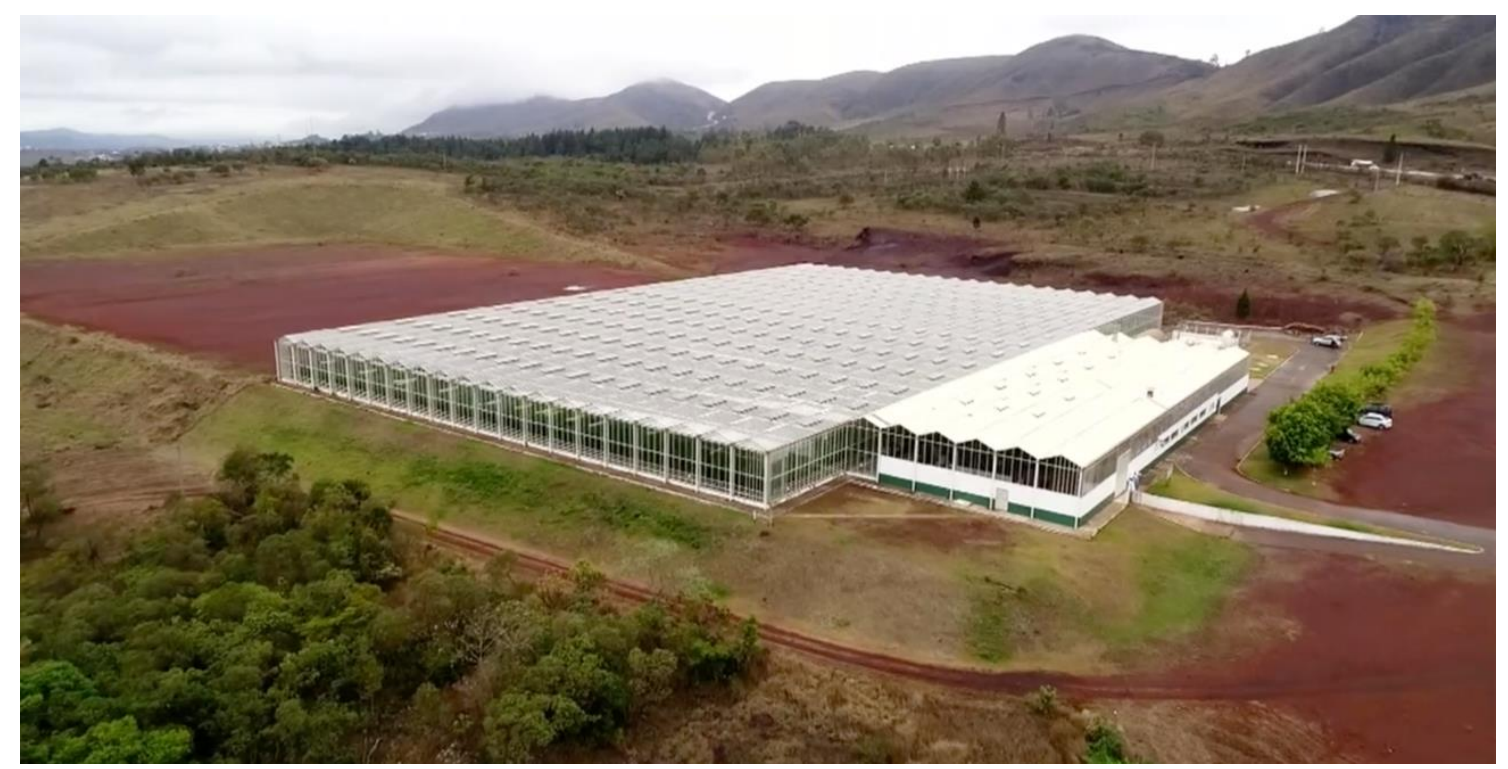

Figura 2 - Estufa em Itabirito (MG)

Fonte: Globo Rural (2017) 
Ainda que o exemplo acima não esteja integrado à malha urbana, a estufa ilustra um modelo de aplicação muito eficiente e facilmente adaptável à terrenos vazios e coberturas de edifícios. Esse é um exemplo de agricultura periurbana que atingiu excelentes resultados em um pavilhão de qualidade projetual, ambiental e social, na qual apenas 18 empregados passam seus dias em excelentes condições de trabalho. Os projetos arquitetônicos e urbanísticos de hortas urbanas e fazendas verticais geralmente são bem simples, ao contrário do que a cenografia de filmes futuristas nos levou a acreditar. No imaginário popular, as fazendas verticais são arranha-céus verdes de altíssima tecnologia, com luzes de LED e maquinários complexos. De fato, esse é um modelo interessante a almejado, mas tem-se percebido que algumas configurações eficientes possuem quatro, cinco andares, grande aproveitamento da energia solar natural, e recursos simples para distribuição de água no cultivo das hidropônicas através de canos de PVC ou até mesmo de bambu.

Entre o que é planejado, o que é construído e que permanece, existe um grande abismo causado por questões imprevisíveis (ROZENSTRATEN, 2018, p. 12). Deve-se estudar o porquê que as atuais fazendas verticais falham para entender onde e como fazer diferente. Mais falhas acontecerão enquanto profissionais de várias áreas estiverem buscando a combinação certa de sustentabilidade, lucro e comida com qualidade. Mas alguns empreendimentos como a Mirai Corp e a AeroFarm obtiveram sucesso, então já sabemos que é possível. Os gêneros produzidos ainda são muito caros, no entanto, novos sistemas de distribuição e produção conseguirão inserir esses produtos em determinados nichos de mercado com algumas vantagens competitivas no que diz respeito às menores distâncias e elevado padrão de qualidade (CARTER, 2011 apud DESPOMMIER, 2010).

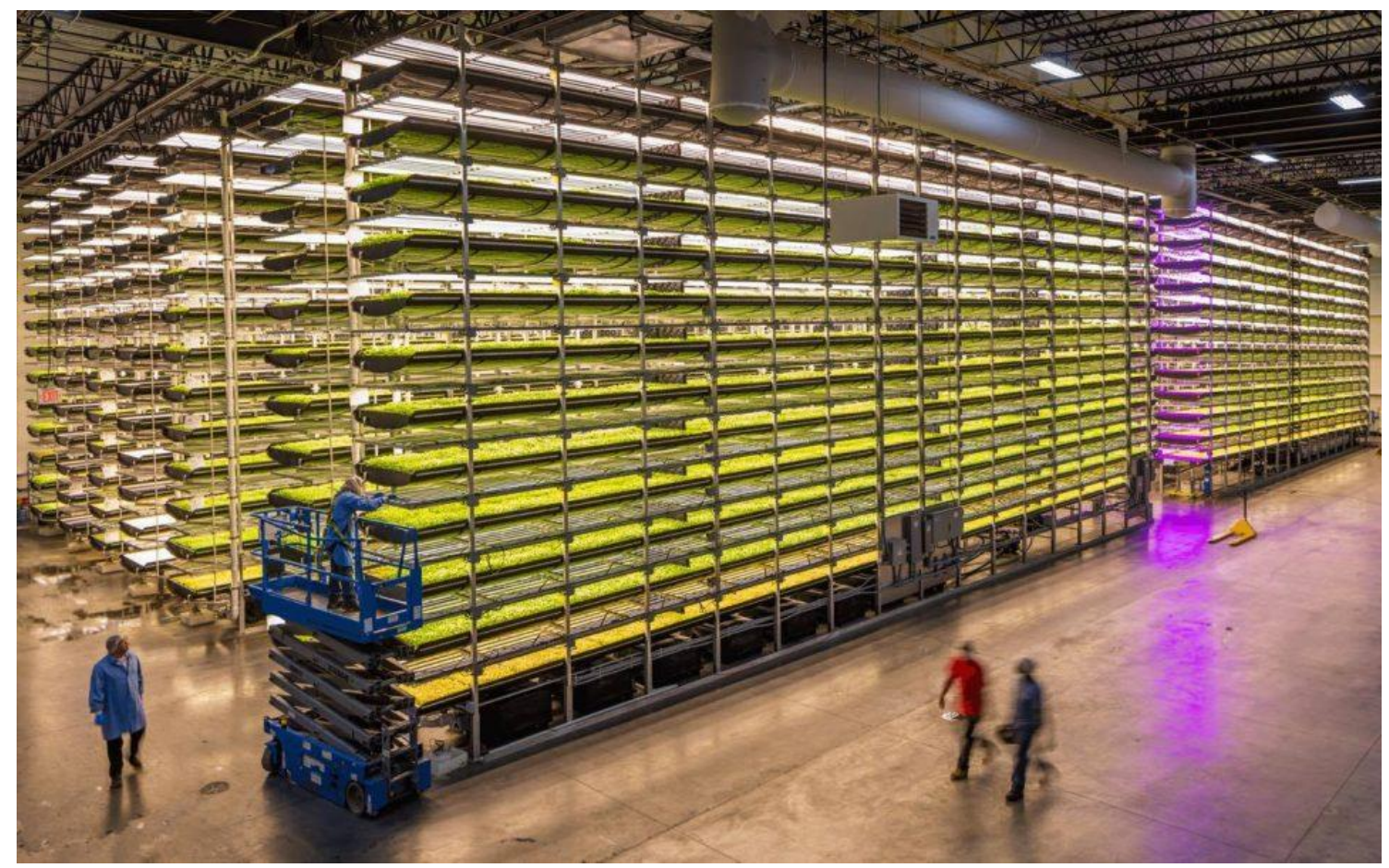

Figura 3 - Fazenda Vertical da empresa AeroFarms Fonte: AeroFarms (2019) 
Arquitetonicamente falando, não há um padrão de construção para esses empreendimentos, tudo depende da dinâmica e do clima local. A Sky Green Farms de Singapura, trabalha em apenas um andar de pé direito alto, plantando e colhendo em 120 torres de alumínio de 9 metros de altura (). Com estrutura metálica e vedações em vidro para permitir a entrada de luz. Enquanto na Coreia do Sul, um antigo túnel desativado foi adaptado para plantio de hortaliças em torres, isoladas da energia solar e iluminadas por lâmpadas de LED cor-de-rosa, outros projetos estão testando sistemas integrados com aquicultura, preferindo a distribuição de espécies em vários andares, setorizando funções diferentes em outros pisos ou blocos.

\section{PROPOSTAS}

É necessário, portanto, rearranjar as tradicionais estufas de configuração horizontal já conhecidas para um formato que conserve espaço através do empilhamento de estufas umas em cima das outras, incorporando-as propriamente na paisagem da cidade e conferindo qualidade ambiental. Espaços abandonados como terrenos baldios e resíduos urbanos podem ser amplamente utilizados, e até mesmo construções inacabadas ou embargadas (considerando reformas em prol da segurança, é claro). Hortas e fazendas de várias alturas podem ser construídas de encontro às necessidades de comércios, instituições e conjuntos habitacionais. Alguns empreendimentos isolados de fazendas verticais de grande porte serão construídos logo nos limites da cidade, onde geralmente há mais terra disponível e acessível em termos econômicos, para a produção em massa de alimentos essenciais, como arroz, trigo, milho e outros grãos (DESPOMMIER, 2010, p. 129-130).

Em termos arquitetônicos, são claras as premissas básicas de uma horta e uma fazenda urbanas: devem ser autossustentáveis, baratas de construir, modulares, duráveis, de fácil manutenção e seguras de operar. No entanto, o desafio reside em como conseguir tais objetivos integrados. As fazendas verticais, independentemente do porte, devem ser projetadas de maneira tal que impossibilitem a entrada de microrganismos e insetos, usando os mesmos recursos aplicados nos projetos de unidades de tratamento intensivo de hospitais. Quando o arquiteto Louis Sullivan afirmou que "A forma segue a função", ele enunciava um dos princípios da arquitetura moderna, mas antes de tudo, um princĺpio definidor da vida na Terra. Todas as estruturas orgânicas assumem determinados formatos em prol de motivos funcionais e são selecionadas naturalmente para crescer e se reproduzir. Portanto, nos projetos das fazendas verticais, arquitetos, engenheiros, agrônomos e economistas devem trabalhar juntos sob esse conceito primordial, para satisfazer as necessidades das plantas e das pessoas, igualmente. Recomenda-se que os espaços interiores sejam altamente flexíveis, permitindo que os trabalhadores reconfigurem a disposição interna conforme as necessidades das colheitas.

As fazendas verticais ainda sustentam um sistema secundário de tratamento de esgoto de maneira natural e sem uso de produto químico algum: através de pequenos poros nas folhas chamados 'estômatos', as plantas transpiram parte da água que puxam pelas raízes. Tirando vantagem dessa atividade natural, alguns setores de plantas podem ser sacrificados para absorver águas cinzas e transpirar uma água puríssima para o ambiente, a ser captada em perfeitas condições de consumo. "Sacrificados", pois apesar de aparentemente saudáveis, esses vegetais não devem ser consumidos, pois 
podem conter microrganismos patogênicos, o que seria muito arriscado no ponto de vista da saúde pública. A água de esgoto é purificada através dos tecidos vegetais e liberada na atmosfera enclausurada das fazendas verticais (DESPOMMIER, 2010, p.174). Na impossibilidade de ingestão dessas plantas, o presente estudo então propõe o cultivo de gêneros destinados à produção de biodiesel, ou produção de algodão - uma das plantações mais contaminadas por agrotóxicos na atualidade.

Um programa de necessidades inicial na configuração das fazendas verticais deverá ter um espaço para o cultivo efetivo de alimentos, escritórios e administração, unidade de controle, berçário para as sementes e mudas, laboratório de controle de qualidade, espaço de descanso e socialização da equipe, espaços didáticos e turísticos para gerar rendas extras, restaurante, mercado ou sacolão. Algumas espécies de peixes cultivadas em tanques podem servir para produzir nutrientes nas águas de irrigação, além do reaproveitamento dessa água em vários canteiros e andares, desde que seguramente monitorados contra doenças e com a constituição química adequada.

A estrutura técnica básica da qual tem-se conhecimento até agora é composta por quatro estruturas principais que podem ser executadas de varias maneiras diferentes: Captura de luz solar e dispersão uniforme ou direcionada nas plantações; incorporação de sistemas alternativos de geração de energia (fotovoltaica, eólica, biomassa) para reduzir gastos e manter uma reserva confiável; emprego de uma estrutura física versátil que sustente e proteja espécies diferentes de maneiras diferentes; e aproveitamento máximo de espaços para compensar o ônus econômico do valor da terra.

As fazendas verticais e hortas urbanas compõem um cenário futuro moderadamente otimista. Seria ideal que a humanidade abandonasse espaços superpopulosos e migrasse de volta para o campo de maneira espontânea e orgânica, como por osmose, até atingir um equilíbrio perfeito entre campo e cidade. Todos em ecovilas, plantando, colhendo e trocando frutas e verduras por escambo. Primoroso, porém pouquíssimo provável. Grande parte das pessoas está muito acostumada a viver em metrópoles, com acesso a um universo dinâmico e cosmopolita, para abandonar tudo isso em troca de uma vida simples e pacata no campo. Ainda que essa segunda opção ofereça uma perspectiva promissora de qualidade de vida. Se tantas milhares de cidades já estão irremediavelmente consolidadas, devemos construir um futuro melhor em cima dessas malhas urbanas, não como Mefistófeles e Fausto no drama de Goethe, mas sim com o mínimo de destruição possível.

\section{CONSIDERAÇÕES FINAIS}

As fazendas verticais e hortas urbanas serão necessárias para garantir a soberania alimentar nos países em desenvolvimento no século XXI. Há décadas as construtoras e incorporadoras já se utilizam da estratégia de solo criado para verticalizar bairros nobres, portanto é igualmente possível verticalizar o cultivo de alimentos em tantos andares quanto forem necessários, proporcionando um uso eficiente do espaço urbano. Essa é uma medida mais do que recomendável, fundamentada no conhecimento de que 
mais de $80 \%$ das terras agricultáveis do mundo já estão sendo utilizadas, e os $20 \%$ restantes não seriam suficientes para suprir a demanda da população em crescimento (DESPOMMIER, 2011). Um dos principais argumentos a favor dessa iniciativa é a economia de água: enquanto o agronegócio é o principal consumidor de água no mundo, as hortas urbanas cultivam espécies hidropônicas que consomem $70 \%$ a menos de água do que a agricultura tradicional (FUTURISM, 2018). Essa prática evita tanto o esgotamento hídrico quanto o esgotamento dos solos: muitas espécies crescem na completa ausência de terra, apenas irrigadas com água cheia de nutrientes provindos da compostagem, enraizadas em tecidos reciclados de PET (SEEKER, 2016).

É inegável a vantagem na continuidade da produção em ambientes controlados independentemente das estações do ano; das intempéries climáticas; e dos desastres ambientais como secas ou enchentes. Além da supracitada sustentabilidade em tantos aspectos, também é necessário combater a dependência de agrotóxicos usados nas plantações. Os agrotóxicos estão comprovadamente relacionados à incidência de câncer e outras doenças crônicas; são substâncias que contaminam o solo, cursos d'água e aquíferos; reforçam a dependência de si mesmos em seu próprio ciclo vicioso; ameaçam os pequenos produtores e aumentam o monopólio de grandes empresas; levam vários países a parar de comprar comida do Brasil; e matam 200 mil pessoas por ano, segundo a ONU (2017c).

A pesquisa defende a necessidade e urgência de conectar conhecimentos arquitetônicos, biológicos, sociais e econômicos no projeto das fazendas verticais e hortas urbanas, evitando o crescimento das pegadas ecológicas e o distanciamento cada vez maior entre o local de origem e o local de venda de alimentos. Deve-se promover equilíbrio entre campo e cidade e combater a hegemonia dos sistemas corporativos tecnológicos de monocultura para exportação, que dificultam os meios tradicionais de subsistência artesanal e agrícola. É fundamental compreender o ambiente construído a partir de uma visão sistêmica e ecológica, com o suporte do Desenho Ambiental e seu impacto direto no projeto de Arquitetura (FRANCO, 1997, p. 31; MCHARG, 1992) e assim, estabelecer diretrizes de projetos para cenários específicos de cidades brasileiras que tenham perspectiva de crescimento ou previsão de colapso.

\section{REFERÊNCIAS}

AEROFARMS. We are transforming agriculture. Disponível em: <https://aerofarms.com> Acesso em 03/03/2019.

BENÍTEZ, Raúl Osvaldo. FAO, Perdas e desperdícios de alimentos na América

Latina e no Caribe. Texto: FAO, 2018 Raúl Osvaldo Benítez. Disponível em: <http://www.fao.org/americas/noticias/ver/pt/c/239394/> Acesso em:17/09/2018

COMITÊ INTERNACIONAL PARA O FUTURO DA ALIMENTAÇÃO E DA AGRICULTURA. Manifesto sobre o futuro da Alimentação e da Agricultura. Florença 2006, 23 p. Disponível em: <http://www.navdanyainternational.it/images/manifesti/cibo/cibo_por.pdf> Acesso em: 26/02/2017. 
DESPOMMIER, Dickson. The Vertical Farm: Feeding the World in the 21 st Century. $1^{a}$ edição. Editora: Picador USA. 2011.311 p.

EMBRAPA. Práticas Agropecuárias. Disponível em:

<https://www.embrapa.br/praticas-agropecuarias> Acesso em: 18/09/2018

FRANCO, Maria de Assunção Ribeiro. Desenho ambiental: uma introdução a arquitetura da paisagem com o paradigma ecológico. São Paulo:

Annablume, 1997. $224 \mathrm{p}$.

GLOBO RURAL, Conheça duas realidades diferentes de cultivo de tomate em MG. Disponível em: <http://gl globo.com/economia/agronegocios/globo$\mathrm{rural} /$ noticia/2017/11/conheca-duas-realidades-diferentes-de-cultivo-detomate-em-mg.html> Acesso em: 18/04/2019

IBGE, Censo 2010. Disponível em: <https://censo2010.ibge.gov.br/> Acesso em: $17 / 09 / 2018$

INOVAÇÃO UNICAMP, Incentivo ao biocombustível desestabiliza mercado de alimentos, dizem relatórios. Disponível em:

<https://www.biodieselbr.com/noticias/em-foco/incentivo-biocombustiveldesestabiliza-alimentos-251011> Acesso em: 22/04/2019

JACOBS, Jane. Morte e Vida de Grandes Cidades. São Paulo Editora WMF Martins Fonts, 2011 . - Coleção cidades), $510 \mathrm{p}$.

MASCARÓ, Juan (Org.); MASCARÓ, Lúcia; FREITAS, Ruskin Marinho de. Infraestrutura da paisagem. Porto Alegre: Masquatro, 2008. 194 p.

MONTANER, Josep Maria; MUXÍ, Zaida. Arquitetura e Política: Ensaios para mundos alternativos. $1^{a}$ Edição, $2^{a}$ impressão. São Paulo: Gustavo Gili, 2014. 253 p.

MÜLLER, Christa. Plante você mesmo. PISEAGRAMA, número 9, 2016. Rona Editora, Belo Horizonte.

ONU, $\mathbf{3 0 \%}$ de toda a comida produzida no mundo vai parar no lixo. Disponível em: <https://nacoesunidas.org/fao-30-de-toda-a-comida-produzida-nomundo-vai-parar-no-lixo/> Publicado em 14/11/2017a. Acesso em: 17/09/2018.

ONU, Apesar de baixa fertilidade, mundo terá 9,8 bilhões de pessoas em 2050. Disponível em: <https://nacoesunidas.org/apesar-de-baixa-fertilidade-mundotera-98-bilhoes-de-pessoas-em-2050/>. Publicado em 22/06/2017b. Acesso em: 17/09/2018.

ONU, Pesticidas matam $\mathbf{2 0 0}$ mil pessoas por intoxicação aguda todo ano, alertam especialistas. Disponível em: <https://nacoesunidas.org/pesticidasmatam-200-mil-pessoas-por-intoxicacao-aguda-todo-ano-alertamespecialistas/> Publicado em 22/06/2017b. Acesso em: 17/09/2018.

THE GREEN POST, Presídio de MG possui horta em que presos cultivam próprios alimentos (e plantas medicinais). Acesso em 22/04/2019. Disponível em: $<$ https://thegreenestpost.com/presos-em-minas-produzem-ate-400-caixas-delegumes-por-mes/> 